\title{
REPRESENTAÇÃO RÉGIA: UMA QUESTÃO DE GÊNERO (SÉCULOS XV-XVII)
}

Royal representation: a matter of gender (XV-XVII centuries)

\author{
Mário Martins Viana Júniora \\ (D) https://orcid.org/0000-0001-5957-7021 \\ E-mail: mario_ufc@hotmail.com \\ Patrícia Rosalba Salvador Moura Costa ${ }^{\mathrm{b}}$ \\ (D) https://orcid.org/0000-0001-8320-9093 \\ E-mail: patriciarosalba@gmail.com \\ a Universidade Federal do Ceará, Centro de Humanidades, Departamento de História,
Fortaleza, CE, Brasil
b Universidade Federal de Sergipe, Programa de Pós-Graduação em Antropologia,
Núcleo de Educação em Ciências Agrárias e da Terra, São Cristóvão, SE, Brasil
}




\title{
RESUMO
}

Este trabalho investiga a existência de uma cultura de Antigo Regime engendrada no Reino de Portugal e em seus domínios coloniais, desde o século XV até o XVII. Para tanto, colocamos sob análise as representações construídas sobre e pelos monarcas. Metodologicamente analisamos dois grupos de fontes documentais: o primeiro remete às cerimônias e aparições do Monarca e seus súditos, e o segundo, aos escritos régios que desvelam, de maneira clara e objetiva, comportamentos, hábitos e costumes marcadamente masculinizantes. Conclui-se que a literatura foi um importante pilar para a manutenção de uma cultura guerreira ibérica em declínio e para a propagação de modelos de masculinidade altamente viris no Reino e em suas colônias.

\section{PALAVRAS-CHAVE}

Masculinidade. Escritos régios. Cerimônias.

\begin{abstract}
This work investigates the existence of a culture of Old Regime engendered in the Kingdom of Portugal and its colonial domains, from the fifteenth century to the seventeenth century. To this end, we analysed the representations constructed on and by the monarchs. Methodologically, we analysed two groups of documentary sources: the first refers to the ceremonies and apparitions of the Monarch and his subjects, and the second, to the royal writings that clearly and objectively unveil behaviours, habits and markedly masculinizing customs. It is concluded that the literature was an important pillar for the maintenance of a declining Iberian warrior culture and for the propagation of highly manly masculinity models in the Kingdom and its colonies.
\end{abstract}

\section{KEYWORDS}

Masculinity. Royal Writings. Ceremonies. 
ste artigo busca aprofundar a reflexão sobre a existência de uma cultura engendrada no Reino de Portugal e em seus domínios coloniais, principalmente, no período de expansão ultramarina. Para tanto, colocamos sob análise as representações construídas sobre e pelos monarcas. Elas foram estruturadas e estruturantes de uma dinâmica expressa na relação entre um ideal de masculinidade e de um masculino ideal que delineava e incitava ações, relações e comportamentos analisados aqui sob uma perspectiva de gênero. ${ }^{1}$

Tomando o gênero como categoria de análise, pudemos desnaturalizar as relações históricas estabelecidas entre os sujeitos e elucidar questões referentes às construções socioculturais erigidas em torno das masculinidades identificadas. Do entendimento do gênero como a atribuição de valores e significados aos indivíduos com base na diferença anatômica dos órgãos sexuais, buscamos aprofundar nossa percepção sobre as relações de gênero, em seus sentidos contingentes, de construção e de invenção.

Os caminhos escolhidos para o estudo ora apresentado seguem duas direções temáticas a partir de diferentes grupos documentais. Por um lado, perscrutamos as cerimônias para compreender qual o significado das festividades no fim do período medieval e durante a modernidade. Analisamos e apresentamos marcações de gênero propaladas para as populações a partir dos atos e aparições do Rei e de seus subordinados.

Por outro lado, realizamos o escrutínio dos escritos régios que descrevem, ainda que de forma idílica, muitas vezes, como deveria ser a educação dos monarcas. Referimo-nos às seguintes obras: o Livro da Montaria, de D. João I (1385-1433); os livros do Leal Conselheiro e o Livro da Ensinança de D. Duarte (1433-1438); a Crônica do Imperador Clarimundo (1522) de João de Barros e o Memorial das Proezas da Segunda Távola Redonda (1567) de Jorge Ferreira de Vasconcelos.

Imbricada em uma tradição marcada pelos aspectos da guerra e pelos valores da cavalaria medieval, esses documentos desvelam o delineamento de um protótipo masculino ideal, o monarca, e uma cultura altamente viril/virilizante. Desde a busca da construção e do controle do aparelho psíquico humano, pela recomendação expressa dos sentimentos, desejos e ações a serem promovidos e evitados, até a indicação de quais objetos fálicos deveriam ser manuseados/utilizados, costura-se um conjunto amplo

\footnotetext{
${ }^{1}$ Buscamos diálogo com os trabalhos pioneiros de Joan W. Scott $(1995,1999,2005)$. Contudo, é fato que os estudos sobre tal conceito tomaram uma proporção bastante ampla, sendo gênero percebido por muitos(as) estudiosos(as) como um "campo de estudos" na atualidade. Para entender o movimento de ampliação dos usos desta categoria, destacamos os trabalhos de Joana Maria Pedro (2005) e Raquel Soihet (2007) que fazem um balanço sobre os estudos de gênero no âmbito nacional e internacional. Para a feitura deste trabalho, importa destacar também as diferentes leituras que realizamos de autores(as) de áreas distintas (e que não necessariamente tratam da temática de gênero, embora contribuam para a discussão): Donna Wilshire (1997) e Monique Wittig (2007), que abordam o tema do feminismo da diferença; Michelle Perrot (1998), Joana Maria Pedro (1998), Eni de Mesquita Samara (2003) e Hildete Pereira de Melo (2001), que contribuíram com estudos sobre a história das mulheres (e da família); Donna Haraway (1995) e Judith Butler (2003) que permitem observar o sujeito como produção discursiva permeada por relações de poder e fazer a crítica a toda forma de naturalização da história, a exemplo da discussão em torno da heterossexualidade compulsória. É importante frisarmos também a importância dos trabalhos sobre masculinidade, como os de Cristina Scheibe Wolff (2011), Durval Muniz (2003), Miguel Vale de Almeida (1995), Pedro Paulo de Oliveira (2004), Pedro Vilarinho (2008), Sócrates Nolasco (2001) e os organizados por Mônica Raisa Schpun (2004) e Ronaldo Pamplona da Costa (1986).
} 
e de longa duração de formas de masculinização dos indivíduos que problematizaremos a seguir.

\section{INVENÇÃO DOS MODELOS MASCULINOS E MASCULINIZANTES: AS CERIMÔNIAS}

Na composição de uma maior abstração do exercício do poder régio, os reinados de D. João II (1481-1495) e de D. Manuel (1495-1521) foram singulares para a História de Portugal ao darem prosseguimento aos empenhos feitos desde o início da dinastia de Avis (1385) em torno da sobrevalorização do Monarca. O esforço dedicado à construção da imagem do Soberano promoveu paulatinamente uma diferenciação entre Rei e Reino, visto que "o Rei passa a ser alguma coisa mais do que um senhor (persona natural), assumindo o que virá a ser a personificação inamovível do Estado (persona pública)" (MAGALHÃES, 1997, p. 63).

Ao lado de um melhor aparelhamento da Justiça e das suas regras, o foco acerca da projeção da imagem do Soberano sobre seus súditos se tornou uma constante por meio de diferentes instrumentos e apresentou uma longa duração até o declínio da monarquia no século XIX ${ }^{2}$ As festividades tiveram uma contribuição singular nessa ampliação da representação régia. As relações entre a festa da realeza, nas suas várias declinações, e o poder régio faziam parte de um sistema de comunicação político mais amplo e inerente às sociedades de Antigo Regime.

As "cerimônias, na sua diversidade, faziam parte integrante de uma coerente 'gramática' de celebração da monarquia e de afirmação e exibição ritual do seu poder, e até mesmo da arma política" (BUESCU, 2011, p. 142). Eram expressas nas aclamações e entronizações dos príncipes, nas entradas régias, nos nascimentos e nos matrimônios dos membros da família real, no cotidiano da vida de corte, nos funerais, nas transladações dos corpos régios. A comunicação do Soberano com os súditos indicava uma hierarquia e uma simbologia de poder na qual ele ocupava uma disposição central.

Dessa posição, além de ser posto e dado a ver como masculino ideal inalcançável, atuava mediante uma economia gestual ditando hábitos, costumes, condutas e comportamentos generificados. Nos eventos ritualísticos, acreditamos que, mais do que a norma, importavam os modelos andrógenos e os exemplos que deveriam ter no Monarca e nos seus ministros mais próximos as suas principais expressões masculinas.

O momento de aclamação do novo rei, por exemplo, era aquele concomitante ao início do luto em relação ao Monarca anterior e que, em Portugal, se revestia de

\footnotetext{
${ }^{2} \mathrm{~A}$ ascensão e declínio de monarquias europeias e seus modelos masculinos hegemônicos correlatos seguem temporalidades específicas conforme cada país/território. Em Portugal, o complexo sistema da "economia do dom" e da "justiça distributiva" (CUNHA, 2000) implicaram caminhos diferentes. Assim, é preciso observar com cautela análises que serviram de modelo para toda a Europa. Referimo-nos, por exemplo, aos clássicos estudos de Nobert Elias (1993a; 1993b) sobre a sociedade de corte em França que tomam os processos de disciplinarização, de controle das emoções e de domesticação dos comportamentos como um "processo civilizador" que tinha como meta final o estado-nação. Apesar de estudiosos sobre masculinidades (OLIVEIRA, 2004) reiterarem o paradigma elisiano em suas análises, faz-se necessário atentar para os riscos de "uma visão teleológica da história" como alerta Le Roy Ladurie (2004) em relação aos trabalhos de Elias.
} 
muitas peculiaridades. Significava o reconhecimento público do pacto selado entre os seus súditos e o seu Soberano que não era sagrado, e tampouco ungido. $\mathrm{Na}$ cerimônia em que o Monarca fazia um juramento obrigando-se à boa governança e à administração da Justiça, fixava-se uma imagem de origem medieval em que todos os homens se curvavam a um só indivíduo em uma posição de reverência: o ajuramentar e os beijos dos subordinados dirigidos à mão do Rei no ritual do beija-mão.

Na disposição cartográfica do cerimonial, eis como eram minuciosamente dispostos os sujeitos para garantir a elevação do Soberano:

Marcado o dia e a hora para a aclamação, o novo Rei sai do Paço vestido de opa roçagante de brocado, a cavalo, cuja rédea leva um importante personagem. Diante dele, o condestável, com o estoque levantado, e ainda à frente o alferes-mor, com o estandarte real. À direita do rei, os senhores, à esquerda, os oficiais-mores e a câmara. No local escolhido para o auto [variável], um teatro devidamente engalanado para a cerimônia, onde estão esperando os prelados. O Rei senta-se no lugar mais elevado e o camareiro-mor entrega-lhe o ceptro de ouro, símbolo da vara da justiça (MAGALHÃES, 1997, p. 64).

Reproduzindo-se a dissimetria social cotidiana e a disposição das esferas de poder naquele evento, o Monarca ocupava não apenas o centro, mas o ponto mais alto para onde deveriam convergir todas as forças e olhares. Mais que isso, no engendramento das ações e dos objetos, os homens reforçavam as imagens de submissão e de subserviência buscando garantir a satisfação e o anseio do novo Rei por meio da concessão do cetro, um bastão curto, objeto fálico, que simbolicamente indicava a proeminência do poder do Soberano sobre os demais.

Estes aspectos apontam como a configuração do poder político no Antigo Regime pode ser analisada a partir de uma perspectiva de gênero, inclusive, retomando a proposta de Joan W. Scott (1995) no sentido de rever e ampliar a noção de político. É possível enxergarmos nesses eventos políticos a invenção e a manutenção dos elos de um ideal de masculinidade singular, haja vista a existência de um pacto firmado entre o Monarca e seus vassalos, isto é, levando em consideração a inclinação voluntária dos homens em garantir a perpetuação de um sistema de identificação do qual faziam e se sentiam parte.

Ao longo dos séculos XV-XVIII, festas desse tipo eram realizadas com o objetivo de atuar diretamente na produção e na circulação das representações e das memórias sociais, buscando atingir os súditos por dentro, mediante o fornecimento de elementos de diferenciação e de identificação. Nesse sentido, o período da União Ibérica (15801640) assumiu um aspecto bastante singular:

Mais tarde, com a morte de Filipe II em setembro de 1598, esse corpo físico/político parece ter sido cortado ao meio e repartido: para um lado, ficou a imagem do Rei [representado nas cerimônias, festas e pinturas]; para o outro, a inteligência do Rei encabeçada pelo valido, que passa a vida administrativa e burocrática da União das Coroas. Essa polarização em imagem 
de um corpo refém da corte teatralizada e corpo administrativo-burocrático é um indício de que a monarquia espanhola estava se tornando mais abstrata (MEGIANI, 2004, p. 154).

A amplitude do Império aquém e além-mar fez emergir com mais afinco o planejamento de várias estratégias que tornassem possível a transformação do Rei ausente em um Monarca presente. E isso ocorria peculiarmente no contexto dos Filipes, considerando-se que em 60 anos de domínio, os reis das duas coroas apenas se fizeram presentes em Portugal por não mais do que dois anos e meio. As cerimônias e as demais festividades constituíram um dos aspectos mais proeminentes das sociedades de Antigo Regime. Assumiram uma funcionalidade importante de comunicação política, poder, hierarquia, transmissão de sentimentos (CARDIM, 2004).

As entradas dos Monarcas hispânicos em Portugal ocorreram em dois momentos: 1581 e 1619, por Filipe II e Filipe III (da Espanha). Mais do que os preparativos e o desenvolvimento das festividades em torno desses eventos (MEGIANI, 2004), importa observarmos aqui as intervenções diretas do primeiro Soberano em ritual marcadamente engendrado na ratificação do seu poder sobre os demais homens, invocando ações e situações de submissão e de constrangimento público aos súditos.

O Regimento acerca das entradas dos reis, muito provavelmente sob a ordem de feitura de Filipe II a partir da observação de vários outros existentes do Desembargo do Paço de Lisboa, é um documento bastante elucidativo para a compreensão desses eventos como rituais virilizantes. ${ }^{3}$ Nele observamos o ditar de formas cognoscíveis de reconhecimento pelo masculino ideal, o Monarca, na composição de um ideal de masculinidade "teatralizado" por meio das performances do recebimento do Rei com o pálio. ${ }^{4}$

Muito regularmente utilizado nas Procissões do Corpo de Deus para levar o Sacerdote do Santíssimo Sacramento, o pálio era uma ornamentação que marcava posição singular e de destaque entre os outros partícipes do evento. Composto por um tecido retangular no alto e cercado por tiras de tecido ou de madeira (sanefas) em suas frentes e laterais, o pálio, ou melhor, as varas de sustentação e de condução do pálio representavam objetos de intensa disputa entre os homens mais próximos do Rei, tanto que o Monarca citava explicitamente a hierarquia para o toque e a condução delas no deslocamento régio pela Cidade ou Vila em que se apresentasse:

Sendo o pálio de oito varas levá-los-ão os juízes, vereadores, e procurador do Conselho que servirem atualmente e o escrivão da Câmara; e as outras duas as levarão os dois vereadores mais velhos que tiverem servido a ano atrás [...]. Ter-se-á o pálio prestes a porta da Cidade ou Vila da parte de dentro nas mãos dos homens da Câmara e das pessoas que o houverem de levar

\footnotetext{
${ }^{3}$ Regimento, do qual ei por bem que se use na entrada de El-Rey nas Cidades e Vilas deste Reino onde houver de ser recebido com pálio. Biblioteca Nacional de Lisboa (BNL), Pombalina, Miscelânea Histórica, Códice 249, p. 341-379.

${ }^{4}$ Para o desenvolvimento desta análise estabelecemos proximidade com a teoria lacaniana quanto às suas considerações sobre o Eu, principalmente na edificação das noções de Eu Ideal e Ideal do Eu e da concepção de Estádio do Espelho (LACAN, 1998).
} 
estarão juntos e acompanhados dos meus julgadores e dos oficiais da Justiça e pessoas nobres [...]. ${ }^{5}$

Apresentava-se, portanto, enquanto o centro de um modelo comportamental masculino, o varão perfeito, engendrando verticalmente significados para os objetos abalizados por princípios andrógenos. Nesse quadro imagético, as varas do pálio que cercavam o Monarca eram investidas de uma simbologia e de poderes ímpares ao externar as dissimetrias socioculturais. Seguravam as varas aqueles que no plano simbólico, social e cultural estivessem mais próximos do centro do poder, do Soberano e, portanto, do cumprimento de comportamentos idealizados. Deveriam representar os que eram mais homens em sociedade. A imagem que ajudavam a delinear era a de um masculino ideal no centro arrodeado por outras formas masculinas semelhantes, mas não igualmente perfeitas.

No entanto, as varas do pálio não constituíam os únicos objetos de satisfação no tratamento e condução das subjetividades, dos anseios e dos desejos dos homens. ${ }^{6}$ A simbologia de poder masculinizante, construtora e mantenedora de um ideal masculino, era impressa em outros objetos de formatos fálicos. Estes, construídos e postos em evidência dentro da cerimônia de entrada régia envolviam ações e comportamentos de submissão e engrandecimento previamente estabelecidos:

[Os condutores do pálio e os demais homens nobres] tanto que lá chegarem à distância de 200 passos pouco mais ou menos se abaixarão e irão juntos até chegarem a mim com suas varas do regimento nas mãos e os oficiais da Justiça com as suas; e as mais pessoas nobres e da governança irão detrás e o vereador mais velho levará nas mãos as chaves da Cidade [...] a vista de todos e chegando-se a mim beijando-as primeiro me dará dizendo as palavras seguintes: esta cidade ou vila entra a V.M. as chaves de todas as suas portas, e dos seus corações de todos os seus moradores e de suas pessoas e fazendas para todo o serviço de S.M. E cita estas palavras me beijara a mão, e depois dele o juíz, vereadores, e procurador do [?] e pessoas que houver de levar o pálio por suas precedências, e depois o Corregedor da Comarca deixando todos as varas e os fidalgos se os houver na terra e do da governança que costumam servir de vereadores procurando evitar todo o tumulto e desordem (grifo nosso). ${ }^{7}$

A entrega das chaves da Cidade ou da Vila pela qual passava o Monarca era seguida pelo indicativo da fala dos indivíduos e pelo ritual do beija-mão, em que todos

\footnotetext{
${ }^{5}$ Regimento, do qual ei por bem que se use na entrada de El-Rey nas Cidades e Vilas deste Reino onde houver de ser recebido com pálio. BNL, Pombalina, Miscelânea Histórica, Códice 249, p. 341-379, p. 341-342.

${ }^{6}$ Para aprofundamento das relações entre objetos de satisfação e pulsões assinalamos a leitura da obra de Peter Gay (1989a) e Juan David Nasio (1989).

${ }^{7}$ Regimento, do qual ei por bem que se use na entrada de El-Rey nas Cidades e Vilas deste Reino onde houver de ser recebido com pálio. BNL, Pombalina, Miscelânea Histórica, Códice 249, p. 341-379, p. 342.
} 
os homens de "precedências" deveriam se colocar em disposição de subserviência em relação ao Monarca. A simbologia direcionada às chaves indicava o pretenso poder Soberano de penetrar não apenas o espaço físico da Cidade, mas a casa dos súditos, suas mentes e seus corpos, se retroalimentando em uma tácita imagem virilizante.

Essa penetração real e imaginária ratificava o poder Soberano do Monarca na sociedade portuguesa de Antigo Regime ao mesmo tempo em que engendrava uma hierarquia masculina peculiar, pois era ditada pelo próprio Rei no apontamento do falo como significante central das relações na festividade. Nesse contexto surgia uma das marcas mais profundas da relação entre o masculino ideal e a cultura masculina.

A imagem fálica para penetração fictícia tinha na chave um falo real que the amparava, isto é, um correspondente coerente para a proposição simbólica das relações de subordinação entre o Monarca e seus súditos e que servia de alicerce para projeção do protótipo masculino e de seus modelos de masculinidade. Daí assinalarmos um dos maiores significados das cerimônias de entradas triunfais: uma atitude viril e dominante diante da almejada passividade dos espaços, dos corações, das mentes e dos corpos abertos, penetrados e submetidos com a incumbência de uma carga simbólica engendrada assimetricamente e centrada no falo para a constituição e a manutenção da ordem no Reino, nas Cidades e nas Vilas.

Essa preocupação do Monarca em atingir visceralmente os indivíduos continha um tácito objetivo de atuar (in)diretamente tanto na estruturação da subjetividade dos súditos, incitando-lhes por dentro, como na composição das memórias sociais e na educação sentimental. Nesse contexto, embora nunca absolutamente, as entradas régias foram fundamentais na evidenciação de processos de incorporação das condutas de gênero, isto é, do aprendizado mediante a "[...] imitação de posturas corporais, gestos, reações psicossomáticas, que têm um significado nas relações sociais, estabelecendo hierarquias, entre as quais a do gênero" (ALMEIDA, 1995, p. 60).

Essa diferenciação criada pelo Rei no cerimonial servia-se não apenas dos objetos e dos gestos, mas também dos animais. Pelo uso e pelo manuseio do cavalo, por exemplo, o Monarca buscava marcar uma hierarquia masculina em uma sociedade já fundamentada, erigida e dividida sob a supremacia das qualidades do cavalo cuja singularidade possibilitou a manutenção da divisão da sociedade entre os nobres (cavaleiros) e os não nobres (peões). ${ }^{8}$

Dentre os fidalgos, no cerimonial, o uso exclusivo do cavalo pelo Rei buscava assinalar uma diferença dentro da diferença: seu poder distinto enquanto cavaleiro em uma sociedade cavalheiresca. ${ }^{9} \mathrm{E}$ isso era indicado no deslocamento do Monarca até a Igreja e no trajeto estabelecido até o seu local de pouso:

[...] e tornando a sair da Igreja, aos degraus dela aonde me houver de tornar a pôr a cavalo tomarão as ditas para as varas do palio e na forma sobredita me levarão até os passos donde houver de

\footnotetext{
${ }^{8}$ Segundo Isabel Dias, o Livro d'Alveitaria, de autoria do Mestre Giraldo (médico do rei D. Dinis) produzido em 1318, indicava a nobreza do cavalo na estruturação e distinção da sociedade entre peões e cavaleiros, sendo este animal "reflexo da excelência do grupo que representa" (DIAS, 1997, p. 22).

${ }^{9}$ Embora tenhamos encontrado o uso de sociedade cavalheiresca para se referir às organizações que ainda tinham por base a cavalaria, preferimos o uso do termo cavaleiresco para frisarmos a diferença entre o cavaleiro e o cavalheiro na perspectiva enveredada por D. Duarte.
} 
pousar e depois de eu me apear largarão as varas e me farão todos mesuras com os joelhos no chão e se despedirão de mim, este se cumprirá como neste se contém sem se alterar em coisa alguma, o qual será assinado pelo Marquês de Lamquer Duque de Franca Vila de [?] destes Reinos João Tavares. ${ }^{10}$

$\mathrm{Na}$ imagem geral que o Monarca buscava criar ele sempre projetava o corpo sobre os corpos dos demais. Assim, quando estava sobre o cavalo ele se colocava em uma posição privilegiada, em uma forma de ver o mundo a partir de cima. E esse era um quadro que se repetia com as mesmas cores no momento em que sua presença a pé deveria envergar a capacidade de visão dos súditos, até o chão, cobrando-lhes posição de reverência ao prostrar-lhes de joelhos. Na altura do olhar do masculino ideal não poderia existir nenhum outro. Tratava-se, portanto, de um exercício complexo de posturas com elevada consciência corporal objetivando atender ao ritual proposto.

Montado em seu cavalo de forma exclusiva, o Rei se apropriava simbolicamente da força do animal, subjugando-o e inferiorizando-o ante sua virilidade, além de mostrar destreza na arte de montar, tão cara aos homens mais nobres. Na ação de domínio da fera, o homem exibia os traços e os comportamentos valorativos que faziam parte e ajudavam a compor a idealização de sua imagem perfeita. ${ }^{11}$

Assim, o uso do próprio corpo de que o Rei lançava mão estava imbricado na utilização que ele fazia do corpo do cavalo e que lhe permitia alçar um prestígio e uma apreciação naquele ritual. Impetrava, portanto, uma imagem masculina que se queria perfeita ao aparecer como o principal cavaleiro das Ordens Militares, engendrando uma economia gestual de montaria muito bem trabalhada e ornamentada. Seus súditos, nas mais diferentes conquistas e avanços do poder português, seguravam-se nessa distinção e procuravam reproduzir tal imagem.

\section{INVENÇÃO DOS MODELOS MASCULINOS E MASCULINIZANTES: OS ESCRITOS RÉGIOS}

A produção bibliográfica sobre a cavalaria e a arte de montaria parecia não ter fronteiras. No Sacro Império Romano-Germânico de Frederico II (1194-1250) tinha-se conhecimento de um tratado em latim acerca da montaria (De arte bersandi) no início do século XIII. Entre os reinos espanhóis, o trabalho de Ramon Llull (1232-1316) foi um dos pioneiros sobre essa temática da cavalaria com O Livro da Ordem de Cavalaria cronologicamente seguido na análise da arte de bem montar pelo Livro de Montaria, per

\footnotetext{
${ }^{10}$ Regimento, do qual ei por bem que se use na entrada de El-Rey nas Cidades e Vilas deste Reino onde houver de ser recebido com pálio. BNL, Pombalina, Miscelânea Histórica, Códice 249, p. 341-379, p. 342.

${ }_{11} \mathrm{Na}$ relação homem-animal planejada e posta a ver de forma ritualística são interessantes as observações de Miguel Vale de Almeida. Mesmo tratando sobre cavaleiros de outro período português (século XX), assinala como continuou semelhante a busca pela manutenção de hábitos, costumes, honras e privilégios da época de Sua Majestade, haja vista que ainda na contemporaneidade "o cavaleiro se apropria e domina os atributos machos do cavalo na luta [elevando sua masculinidade] ao quadrado por privilégio; enquanto que a dos homens a pé não é mais do que a que têm no dia-a-dia" (ALMEIDA, 1995, p. 209).
} 
castelão, do Rei castelhano Alfonso XI (1311-1350). Esse conjunto de obras influenciou a escrita dos primeiros Monarcas portugueses da dinastia de Avis. ${ }^{12}$

Em Portugal, amplamente conhecido e citado pela historiografia, ${ }^{13}$ o Livro da Montaria, de D. João I (1385-1433), foi o primeiro exercício de um tratado escrito sobre o modo de proceder à caça, versando, concomitantemente, sobre aspectos técnicos, filosóficos, políticos e morais, e focando principalmente no resgate da dignidade da arte da montaria para ensiná-la aos mais nobres, pois entendida como um "jogo de reis":

D. João I restabelece o vínculo entre montaria e realeza, de há muito, segundo afirma, ignorado. Torna evidente que a ninguém mais que ao Rei aproveitam os benefícios da montaria, atrás enunciados e agora resumidos, para que não restem dúvidas sobre a legitimidade da designação encontrada pelos antigos para aquela prática: "joguo de rreys" [...]. Finalmente, ao quadro da excelência da montaria o autor acrescenta o fato de não haver conhecimento de que algum Rei monteiro tivesse sido mau (indigno, incompetente), o que significa que aquela requer e desenvolve nos que se lhe dedicam qualidade morais específicas (DIAS, 1997, p. 34).

O Livro da Montaria do Mestre de Avis, além de incorporar a ideia de manutenção e de observação das atividades militares por meio do lazer, implicava o caráter vocacional da montaria ao Soberano e, dessa maneira, viabilizava a reprodução da dissimetria que havia entre os Estados sociais, galgando um lugar privilegiado para as práticas de montaria na composição de uma cavalaria tomada como sinônimo de nobreza, desde o século XIII (MATTOSO, 1985).

O escrito de D. João I era, portanto, uma ferramenta de tentativa de sustentabilidade dos ideais de cavalaria como aspecto de identificação masculina para a nobreza portuguesa. O Monarca arquétipo, tal como na imagem de Felipe II, ao entrar em Portugal montado em seu cavalo usava da arte da montaria para perpetuar sua distinção em relação aos demais, tanto no nível social e político como na ratificação de uma hierarquia masculinizada e composta apenas por homens.

O enaltecimento das atividades e das minuciosas práticas guerreiras e a conciliação entre lazer e administração foram pontos retomados e ampliados pelo infante $D$. Duarte nos livros do Leal Conselheiro e do Livro da Ensinança. Acerca da complexidade deste vale retomarmos a análise de Risonete de Souza:

O Livro da Ensinança de Bem Cavalgar Toda Sela, suja "scyencya" D. Duarte tem a consciência de ser o primeiro a tratar por escrito, codifica uma série de comportamentos que, no seu conjunto, visam restaurar exercícios físicos, como cavalgar, manejar lanças, atirá-las, ferir com espada e lutar; apresenta também modelos de ação, de que o autor foi e é exemplo. As passagens de prosa reflexiva que integra reforçam os objetivos

\footnotetext{
12 Segundo Megiani (2004, p. 162), a autoria do tratado siciliano seria de responsabilidade de um cavaleiro germânico conhecido por Guicennas.

${ }^{13}$ Cf. Buescu (2011, p. 144): Alves ([19--]), Araújo (1990), Gomes (1995), Gouveia (2000), Cardim (2001), Paiva (2002).
} 
da modelação dos costumes e a fixação de estruturas socio-políticas que garantem o normal funcionamento de uma sociedade que se organiza em torno do poder régio; chamando assim a atenção para a exemplaridade do rei, ou visando fazer dele o motor da engrenagem social contribui inevitavelmente para o fortalecimento desse poder e das convicções que ele representa. [...] um projeto de educação física, mas também moral, psíquica e intelectual do nobre (SOUZA, 2001b, p. 92-93).

Assim como o tratado de D. João I, o manual de montaria escrito posteriormente por D. Duarte foi alvo de inúmeros estudos. ${ }^{14}$ Dividido em três grandes partes (a vontade, o poder e o saber) compostas por 66 capítulos, sendo a primeira parte formada por 4 , a segunda por 2 e a última distribuída em 60, o Livro da Ensinança buscava perpetuar entre os portugueses o enobrecimento da montaria, tida como prática desportiva dos reis, pelo foco no ensino da arte de cavalgar, de dominar e de submeter o mais nobre dos animais, o cavalo, mediante a vontade, o poder e os saberes masculinos. ${ }^{15}$

Anunciando características renascentistas e amparando-se em textos clássicos, nada mais apropriado do que o próprio Soberano D. Duarte para erigir um texto dedicado ao auxílio dos homens na inserção nos jogos dos reis. ${ }^{16}$ Ali tentava ensinar não apenas o domínio do animal irracional, mas o autocontrole, o comando de si. $\mathrm{O}$ foco de sua escrita era o homem, o seu comportamento. Daí a amplitude do tratado para além das questões técnicas, buscando atingir profundamente o comportamento dos indivíduos, à medida que tratava de receios, medos, vontades, desejos e outros aspectos de cunho subjetivo.

Provavelmente um dos aspectos mais relevantes da escrita do Livro da Montaria foi a tentativa de legitimação e de reconhecimento da nova dinastia. Para tanto, $D$. João I tomou a ascensão dos Avis por uma postura e uma perspectiva masculinizantes, privilegiando a montaria entre várias outras atividades pela sua característica fundamental de desporto viril. Dito de outra maneira, o que o Monarca buscava era o engendramento másculo da nova linhagem de reis e de súditos.

A distinção e a marcação de posição do novo Monarca se davam justamente no sentido de buscar resgatar, ampliar e manter os valores guerreiros com base na arte equestre e nos princípios da cavalaria que pareciam ter sido minimizados e postos de lado pelos reis antecessores. Enquanto os reis anteriores da dinastia de Borgonha baseavam suas atividades lúdicas na cetraria aberta às mulheres, com possível efeminação, portanto, os Monarcas de Avis procederam a uma elevação de práticas

\footnotetext{
${ }^{14}$ Os pormenores estruturais e de conteúdo das três obras produzidas pelos pioneiros de Avis, pai e filho, foram exaustivamente analisados em outros trabalhos. Aqui importa observarmos as conjunturas de produção e os propósitos dos tratados para entendermos como eles expõem a contingência das características tidas como masculinas. Nesse sentido, assinalam uma melhor compreensão da divulgação por grande espaço e largo período da imagem do Rei arquétipo montado em seu cavalo. Cf. Mongelli (2001), Dias (1997) e Marques (2001).

${ }^{15}$ De acordo com Fernando Maués (2001, p. 204) esse tratado encontrava-se "filiado a uma literatura técnica que remonta a obras clássicas [escritas por Xenofonte] às quais vem se juntar a tradição de textos cinegéticos castelhanos e portugueses".

${ }^{16}$ Embora Roger Chartier (1998b) alerte sobre a dúvida de autoria, sugerimos a autoria do livro pelo Rei com base nos apontamentos de outros autores(as) que, inclusive, assinalam variações na escrita do Soberano (DIAS, 1997; MAUÉS, 2001).
} 
consideradas mais varonis, pois em consonância com o caráter belicoso e violento dessas práticas. Essa era a tonalidade que se buscava conferir ao novo escudo de armas elevado no Paço, possuindo no comportamento dos homens uma composição identitária virilizante de diferenciação fundamental entre as duas dinastias.

Embora iniciados nas atividades de letras fomentadas pela dinastia de Avis, a função guerreira permanecia como fulcral na formação dos moços-fidalgos. Fosse por meio de uma aprendizagem explícita no manuseio de armas ou em uma escala mais implícita evidenciada no cotidiano dos pequenos gestos, na linguagem ou nas questões lúdicas, fomentava-se um aprendizado masculino abalizado pelas noções de guerra e de violência que tinham lugar central para a formação dos homens:

Príncipes e os nobres deviam, pois, aprender desde cedo a
montar e a bem cavalgar, a exercitar-se em todas as armas, e
a iniciar-se nessa atividade tão profundamente enraizada na
cultura aristocrática que era a caça. No início do século XVI a
aprendizagem do príncipe D. João, filho de D. Manuel e futuro
monarca, e dos moços-fidalgos que com ele se criavam passou
portanto também por uma precoce iniciação nestes outros
saberes tão valorizados [...]. Com onze anos de idade, D. João
acompanhava já o rei D. Manuel, grande amante da caça e da
montaria, nas suas frequentes incursões venatórias [e talvez] ali
matou o seu primeiro javali (BUESCU, 2011, p. 43).

Tão bem expressa nas entradas e em outras cerimônias régias, como visto acima, a arte da montaria reunia os atributos do guerreiro e atuava incisivamente na configuração de um perfil masculino hegemônico baseado na representação do cavaleiro. ${ }^{17}$ Assim, a representação dos reis de Avis tinha semelhança àquela pintada quase dois séculos depois na entrada triunfal de Felipe II em Lisboa, cuja repercussão se esperava que alcançasse o maior número de partes do Império, desde a Ásia à América portuguesa. Ambas indicavam o arquétipo régio como um masculino ideal, com a peculiaridade de que os primeiros Monarcas registraram em sua própria escrita as qualidades advindas de experiências pessoais pretéritas andrógenas.

Esses registros auxiliavam na superação da proeminência bibliográfica da cetraria encontrada na dinastia de Borgonha e aprofundavam o contato literário com os reinos de Espanha na busca da revalorização do perfil guerreiro. Aliás, a Península Ibérica foi um palco privilegiado para o avanço da literatura sobre caça com destaque para a arte da montaria, haja vista a influência e união da tradição germânica e árabe nessa região, tal como na Sicília normanda. Foi em diálogo com a cultura belicosa e viril dos espanhóis que D. João I escreveu seu tratado. ${ }^{18}$

\footnotetext{
${ }_{17}$ Sobre masculinidades hegemônicas e subalternas, ver Connel (1995) e Connel e Messerschmidt, (2013). Almeida chama atenção para a "capacidade de impor uma definição específica sobre outros tipos de masculinidade, o que significa que o modelo exaltado corresponde, na realidade, a muitos poucos homens [ou que] várias outras masculinidades não hegemônicas subsistem, ainda que reprimidas e autorreprimidas por esse consenso e senso comum hegemônico, sustentado pelos significados simbólicos 'incorporados'" (ALMEIDA, 1995, p. 155).

${ }^{18}$ Para aprofundamento sobre a difusão literária na Península Ibérica, ver: Risonete Sousa (2001) e Isabel Ramírez (1992).
} 
Contudo, diferente do pai que "apesar de demonstrar predileção pelos jogos viris, não [condenava] os jogos de solaz", D. Duarte assumiu uma postura ríspida aberta contra as atividades recreativas que não estivessem relacionadas com a prática de montaria, isto é, com a preparação do corpo e do espírito para a guerra (SOUZA, 2001a, p. 198). A grande insatisfação de D. Duarte era para com a proliferação dos hábitos e costumes desvirilizantes em sua corte:

Destas manhas acima escritas que a cavalo se costumam fazer, escrevi assim largamente por algum costume e grande afeição que delas houve. $E$ isso me dê das manhas outras de força, ligeirice, e braçaria que os cavaleiros e escudeiros em esta terra muito vantajosamente sabiam, e usavam de fazer, de que agora os vejo minguados o que muito me despraz (sic), não prestando ditos nem conselhos com alguma parte desensinança [...], por que tanto acostumaram a fala das mulheres, e puseram todas suas tenções com grande desejo em se trabalharem de bem trazer, calçar, jogar a pela, cantarem e dançarem, por Ihes seguirem as vontades que mostram principalmente destas manhas [...] não querem aprender (DUARTE, 1843, grifo nosso).

A aproximação dos homens do universo cortesão de lazeres e jogos de solaz era considerada um estreitamento de laço com o universo feminino. Daí a observação e queixa do Monarca quanto aos "homens minguados", isto é, compreendidos pela falta, pela desigualdade e pela diminuição de suas virilidades. Na construção e na manutenção do perfil masculino operado pela nova dinastia de Avis, as atividades menos violentas e cortesãs, como as conversas e falas em tons femininos, o trajar cortês, o jogar a "pela", o dançar e o cantar, eram indicados como declinantes da imagem e das práticas do guerreiro.

Para alguns(mas) historiadores(as), como Vera Dias (1991), a obra de D. Duarte representava a expressão agonizante e desesperadora de uma nobreza feudal de base cavaleiresca que se defrontava com a difusão de um incipiente modo de vida burguês. Sobre as mudanças conjecturais em Portugal quinhentista, a autora chegou mesmo a afirmar o avanço do capital com a correspondente derrocada da honra como um valor fundamental. ${ }^{19}$

De uma forma ou de outra, o que D. Duarte buscava combater nos hábitos dos homens era o "amolecimento" daqueles que assumiam posturas muito próximas das tidas como próprias das mulheres, efeminadas. O endurecimento desses sujeitos era proposto por uma educação que levasse ao preparo físico e espiritual alicerçado na vontade, no poder e no saber. Para tanto, as caçadas, os torneios, as justas, os jogos violentos e os exercícios equestres eram tomados como importantes atividades viris pelo Monarca.

Os objetivos dos diferentes reis eram semelhantes: atuar, influenciar e buscar delinear a subjetividade dos indivíduos. Por subjetividade entendemos as formas de prazeres válidas, os signos de valoração, distinção e identificação, além da construção

\footnotetext{
${ }^{19}$ Sobre masculinidades aristocráticas e feudais, sugere-se a leitura do volume 1 da coleção francesa História da virilidade. A Construção social da masculinidade de Oliveira (2004) também merece destaque, desde que observados riscos de análise apontados por Viana Júnior (2017).
} 
e da canalização dos desejos e das vontades, mas também das fobias e dos medos. E nessa educação das sensibilidades e das subjetividades masculinas os objetos eram investidos de simbologias singulares consoantes as atividades virilizantes.

Nas várias violências gestadas discursivamente pela expectativa do Soberano, imbricadas às atividades de guerra e relacionadas com a montaria, os desejos mais íntimos dos homens eram canalizados para objetos de contentamento correspondentes em espécies de jogos de equivalência e de substituição que deveriam convergir e materializar as vontades. Assim, o manuseio dos objetos investidos de elevada simbologia engendrada era ensinado pelo próprio D. Duarte, em especial, na quinta subparte da última parte do Livro da Ensinança:

Quadro 1 - Livro da Ensinança de bem cavalgar toda sela

\begin{tabular}{|c|c|}
\hline Cap. & Título \\
\hline 1 & de ser solto e da soltura da vontade \\
\hline 2 & da disposição do corpo, do saber, da manha, e da usança dela \\
\hline 3 & $\begin{array}{c}\text { da declaração de algumas manhas que se a cavalo cortumam fazer de que-se adiante } \\
\text { da ensinamento }\end{array}$ \\
\hline 4 & do ensinamento de trazer a lança de só mão na perna e ao colo \\
\hline 5 & do ensinamento do reger [a lança] \\
\hline 6 & do ensinamento de bem encontrar \\
\hline 7 & da ensinança de endereçar bem o cavalo na justa \\
\hline 8 & por que se demostram quatro vontades que são em nós, e como por elas nos devemos reger \\
\hline 9 & $\begin{array}{c}\text { em que se demonstra por que virtudes nos aderençamos (sic) a desesperar as três } \\
\text { vontades suso escritas e seguem a quarta }\end{array}$ \\
\hline 10 & $\begin{array}{c}\text { como os que justam erram por desordenança de vontade apropriando todo às quatro } \\
\text { vontades suso escritas }\end{array}$ \\
\hline 11 & por quem se da ensinança da maneira quem em monte haverá de encontrar \\
\hline 12 & do ensinamento de ferir com lança de sobremão \\
\hline 13 & do ensinamento de remessar \\
\hline 14 & da maneira do ferir de espada \\
\hline 15 & do louvor das manhas \\
\hline 16 & dos erros da luta brevemente escritos \\
\hline
\end{tabular}

Fonte: Duarte (1843, p. 60-105).

Especificamente os capítulos 4, 5, 7, 12, 13 e 14 tratavam com minuciosidade da utilização das armas pelo cavaleiro. Lanças, paus, varas, espadas, além de outros objetos fálicos faziam parte dos acessórios cavaleirescos e eram detalhados em seus usos para atingir as presas na atividade de caça ou os adversários nos jogos e nas guerras. Evocando uma aritmética gestual que aproximasse os corpos do cavaleiro e do cavalo de forma bastante sincronizada, apresentava-se uma performance a ser alcançada, como nos casos do ferimento proferido por espadas:

Sobre os avisamentos (sic) para bem ferir de espada a mim parece que razoadamente a cavalo se pode ferir por quatro maneiras. Primeira de talho travesso. Segunda de revés. Terceira sedente de cima para fundo. Quarta de ponta. E a primeira e a segunda me parecem melhores para ferir qualquer homem a cavalo que ande de besta. E para dar grande golpe de talho deve ferir vijnda ( $\mathrm{sic}$ ) do cavalo e do corpo, e da soltura do braço 
todo juntamente. E que isto achei em torneio muito aprovado [...] (DUARTE, 1843, p. 98).

O Rei esperava que a atividade acima e não as danças e os cantos propiciassem prazer aos homens. Nesse sentido, arquitetava-se uma prática que servisse como elemento distintivo e identitário e que, por etapas e formas diferenciadas, elegia a espada como um dos instrumentos primordiais. Era por meio dela que os homens podiam controlar e manter afastados alguns de seus medos e inimigos.

Nessa dinâmica, o homem que cavalgava bem era também um bom homem, ou seja, aquele que melhor dispunha do saber técnico da montaria (que incluía domínio sobre armas) apresentava ao mesmo tempo um comportamento virtuoso. O Livro da Ensinança sustentava uma ideologia em que a concepção sobre o cavaleiro era a de que ele seria "tecnicamente competente e moralmente irrepreensível" (DIAS, 1997, p. 14). Bem e bom, portanto, imbricavam-se. Ademais, aprimorava a capacidade guerreira do indivíduo e erigia-se como um dos meios viáveis para obtenção da honra masculina.

Assim, entre o contexto de produção escrita dos reis da dinastia de Avis no século XV e a entrada de Felipe II no final dos Quinhentos havia uma aproximação de pensamento: a virtude exterior era nada mais do que a exposição da virtude interior. Daí a preocupação dos Monarcas na excelência da cavalgadura aprendida e empreendida como um elemento primordial de identificação e diferenciação da nobreza.

Ainda que espaçados em quase dois séculos, todos esses elementos conjuntamente observados formavam partes de semelhantes estratégias de tratamento dos súditos em que sobressaíam e dominavam os princípios andrógenos. Assim, da mesma maneira que havia uma significação da chave da Cidade na entrada de Felipe II houve uma estruturação simbólica construída em torno dos vários objetos fálicos (como a espada e a lança) nos livros dos dois Monarcas de Avis. E no cavalo a proximidade e a singularidade de significados permaneceram: também investido simbolicamente como diferenciador dos grupos sociais, nele todos aqueles elementos eram amplificados.

Essa formação de uma personalidade viril e geral encontrava ressonância ainda nos espelhos dos príncipes, nas novelas cavaleirescas e na celebração de uma memória oficial elaborada a partir dos grandes feitos e heróis de Portugal. Segundo João Palma-Ferreira (1998, apud VASCONCELOS, 1998) entre os séculos XVI e XVII houve uma conjuntura propícia para o culto de mitos criados pelos escritos ancorados nos valores da cavalaria. Para atender ao Monarca, à sociedade de corte e à aristocracia de forma mais ampla, dois livros de espelhos dos príncipes disfarçados em romances se sobressaíram: a "Crônica do Imperador Clarimundo" (1522) de João de Barros e o "Memorial das Proezas da Segunda Távola Redonda" (1567) de Jorge Ferreira de Vasconcelos.

Tomando como parâmetro o "Amadis de Gaula" escrito por Garcia Rodrigues de Montalvo em 1508 e de ampla circulação na Península Ibérica, o Memorial escrito por Vasconcelos trazia dissolvido em seu texto as regras da cavalaria indicadas por Ramón Lull. ${ }^{20}$ Como livro político, destinava-se ao príncipe D. Sebastião (Monarca

\footnotetext{
${ }^{20}$ Segundo João Palma-Ferreira (1998, p. VIII), as regras eram estas: $1^{\circ}$ o princípio da cavalaria, $2^{\circ}$ o ofício do cavaleiro, $3^{\circ}$ o exame que o escudeiro deve fazer para entrar na Ordem da Cavalaria, $4^{\circ}$ a maneira de ser armado cavaleiro, $5^{\circ}$ o significado das armas do cavaleiro, $6^{\circ}$ os costumes do cavaleiro e $7^{\circ}$ a honra cavaleiresca.
} 
entre 1557-1578) e a seus contemporâneos, como Diogo Botelho, ${ }^{21}$ continuando o esforço desprendido pelos reis D. João I (1385-1433) e D. Duarte (1433-1438) na valorização dos costumes cavaleirescos.

Ao resgatar a lendária história do Rei Arthur, por exemplo, o livro de Vasconcelos apresentava para o contexto português uma filiação longínqua e imaginária no sentido de legitimar seus monarcas enquanto pertencentes à Ordem da Cavalaria. Assim, o autor procedeu à invenção do Rei de Sagramor como descendente distante do ciclo arturiano e tentou corporificá-lo na pessoa de D. João III (1521-1556). Este, imbuído da autoridade histórica que Ihe era cabida, deveria ter realizado todas as façanhas listadas na obra, mas sua morte prematura comprometeu a intencionalidade do livro de imbricar o corpo do homem à representação masculina do Rei. Contudo, parece não haver dúvidas que tal trabalho continuou a servir de espelho na educação do príncipe e de seus amigos. ${ }^{22}$

Ademais, a obra indicava vários outros hábitos, costumes, práticas e comportamentos que seriam próprios dos homens cavaleiros. Torneios, justas, armas "cristalinas", aventuras míticas, jornadas fantásticas entre outros aspectos compunham o discurso de invenção do cavaleiro ideal. Dentre os 48 capítulos, por exemplo, a ideia do varão protetor da mulher era uma constante nos capítulos 11, 12, 21 e 25 que remetiam aos socorros das donzelas e das rainhas. Neles, mais uma vez, evocava-se a tradição cavaleiresca e a imagem do masculino ideal:

Nestas contemplações caminhava o cavaleiro das armas cristalinas [...] quando pelo mesmo caminho contra ele vinha apressada uma donzela em um palafrém andador e soberbo. E sendo já perto dele, da mata saiu um Leão que de um salto, em passando, Iho escalou pelas ancas, sem fazer dano a donzela, a qual caiu logo com um grande grito. E [...], ele pondo mui rijo as pernas ao cavalo, com a lança baixa foi levar o Leão que estava encarniçado no palafrém [cavalo da dama]. O cavaleiro, sem passar por diante, voltou logo o cavalo que, com medo do Leão, fez volta como uma ave, e levando da sua boa espada, vindo já o Leão sobre ele, tomou-o com um revés pela vazia que o partiu com dois tão levemente que mais pareceu dita [sorte] que cavalaria. Feito isto, ficando muito seguro, desceu-se do cavalo por acudir à donzela trespassada do temor [e], disse-lhe: [...] - A profissão de meu ofício, me obriga nunca faltar um ponto do serviço das donzelas. Sobre isto, de meu natural sou-lhes eu tão inclinado que não Ihes saberia negar a própria vida [...] (VASCONCELOS, 1998, p. 63-64).

A representação acima encontrava estreita ligação com aquelas construídas no Livro da Montaria, no Livro da Ensinança e no Regimento da entrada de Felipe II, assinalando a longa duração das tentativas de nutrir um ideal de masculinidade alicerçado

\footnotetext{
${ }^{21}$ Antes de ser nomeado Governador-Geral do Brasil, em 1602, Botelho combateu ao lado de D. Sebastião na Batalha de Alcácer Quibir, em África: "Capitão na Batalha de Alcácer [...] na África, [Diogo Botelho] levou dois navios a sua custa e a se achar na dita batalha com cinco de cavalo e doze arcabuzeiros". Arquivo Nacional da Torre do Tombo (ANTT), Chancelaria de Filipe I, Livro 12, fl. 234.

${ }^{22}$ Para aprofundamento da temática, ver Hermann (1999).
} 
nos princípios da cavalaria. De uma maneira ou de outra, os cavaleiros imaginários que surgiam desses documentos encontravam-se pelas qualidades e aventuras listadas pela pena dos escritores.

E na composição de uma cultura generificada, o masculino ideal encarnado nos mais diferentes reis ao longo dos séculos intervinha na construção e na montagem de situações e de cenas ritualizadas que auxiliavam na manutenção do ideal de masculinidade. Todos esses aspectos deveriam ser postos a ver, elevados em seu aspecto estético como na "mostrança" indicada por D. Duarte como uma demonstração exterior das virtudes interiores.

\section{CONSIDERAÇÕES FINAIS}

Buscamos demonstrar o quadro de algumas das festividades e de alguns dos ensaios mundanos criados visando a constituição e manutenção dos comportamentos varonis perante as mudanças ocorridas desde a ascensão da dinastia de Avis, que viveu a crise de uma nobreza recém-elevada: "uma classe guerreira sem guerra" (MAUÉS, 2001, p. 232). Iniciativas de tentar manter a hegemonia de um modelo de masculinidade que ia sendo carcomido pelas relações dos homens no tempo e que nunca se efetivou de forma absoluta. Em suma, buscava-se levantar a espada por meio da pena, isto é, a literatura servia de importante suporte para projeção da cultura guerreira ibérica não raras vezes abalada.

Essas eram algumas das tentativas de imposição da(s) maneira(s) de ser homem pelo simples confronto com a imagem ideal do Monarca ou pela invenção de comportamentos de gênero que deveriam se propalar por todo o Império Ultramarino Português. Dito de outra maneira: formas de interação na dinâmica entre o masculino ideal e o ideal de masculinidade, uma cultura ibérica altamente marcada pelo gênero que cruzou séculos e oceanos.

\section{REFERÊNCIAS}

ALMEIDA, Miguel Vale de. Senhores de si: uma interpretação antropológica da masculinidade. Lisboa: Fim de século, 1995.

ALVES, Ana Maria. As entradas régias portuguesas: uma visão de conjunto. Lisboa: Horizonte, [19--].

ARAÚJO, Renata de. Lisboa: a cidade e o espetáculo na Época dos Descobrimentos. Lisboa: Horizonte, 1990.

BUESCU, Ana Maria. Na corte dos reis de Portugal: saberes, ritos e memórias: estudos sobre o século XVI. Lisboa: Colibri, 2011.

CARDIM, Pedro. Prefácio. In: MEGIANI, Ana Paula Torres. O Rei ausente: festa e cultura política nas visitas dos Filipes a Portugal (1581 e 1619). São Paulo: Alameda, 2004. p. 4-9. 
CARDIM, Pedro. Entradas solenes, rituais comunitários e festas políticas: Portugal e Brasil, séculos XVI e XVII. In: JANCSÓ, István; KANTOR, Íris. Festa, cultura e sociabilidade na América portuguesa. São Paulo: Edusp, 2001. p. 97-124.

CONNEL, Robert W.; MESSERSCHMIDT, James W. Masculinidade hegemônica: repensando o conceito. Estudos Feministas, Florianópolis, v. 21, n. 1, p. 241-282, jan./ abr. 2013.

CONNEL, Robert W. Masculinities. Cambridge: Polity Press, 1995.

COSTA, Ronaldo Pamplona da. Macho, masculino, homem. Porto Alegre: L\&PM, 1986.

CUNHA, Mafalda Soares da. A Casa de Bragança 1569-1640: práticas senhoriais e redes clientelares. Lisboa: Estampa, 2000.

DIAS, Isabel. A arte de ser com cavaleiro. Lisboa: Estampa, 1997.

DIAS, Vera Lúcia Pian Ferreira. Livro da ensinança do bem cavalgar toda sela: contradições entre o mundo mental da nobreza e as transformações econômicassociais no século XV em Portugal. 1991. 152 p. Dissertação (Mestrado em História) - Instituto de Filosofia e Ciências Sociais, Universidade Federal do Rio de Janeiro, Rio de Janeiro, 1991.

DUARTE, Dom. Livro da ensinança de bem cavalgar toda sela. Lisboa: Typ. Rollandiana, 1843.

GOUVEIA, António Camões. La fiesta y el poder. El Rey, la corte y los cronistas Del Portugal del siglo XVI. In: Espanha. La fiesta em la Europa de Carlos V. Catálogo de Exposição (19/09/2000). Sevilha: Real Alcázar, Sociedad Estatal para la Conmemoración de los Centenarios de Felipe II e Carlos V, 2000. p. 97-124.

HARAWAY, Donna. Saberes localizados: a questão da ciência para o feminismo e o privilégio da perspectiva parcial. Cadernos Pagu, Campinas, v. 5, p. 7-41, 1995.

HERMANN, Jacqueline. No reino do desejado: a construção do sebastianismo em Portugal (séculos XV e XVII). São Paulo: Companhia das Letras, 1998.

LACAN, Jacques. O Estádio do Espelho como formador da função do eu - tal como nos é revelada na experiência psicanalítica. In: LACAN, Jacques. Escritos. Rio de Janeiro: Zahar, 1998. p. 96-103.

LE ROY LADURIE, Emannuel. Saint-Simon ou o sistema da Corte. Rio de Janeiro: Civilização Brasileira, 2004. 
MAGALHÃES, Joaquim Romero (coord.). História de Portugal: no alvorecer da modernidade (1480-1620). Vol. 3. Lisboa: Estampa,1997.

MARQUES, António Henrique Rodrigo de Oliveira. Introdução. In: MONGELLI, Lênia Márcia (coord.). A literatura doutrinária na Corte de Avis. São Paulo: Martins Fontes, 2001. p. 11-21.

MATTOSO, José. Ricos-Homens, infanções e cavaleiros: a nobreza medieval portuguesa nos séculos XI e XII. $2^{a}$ ed. Lisboa: Guimarães Editores, 1985. (Col. História e Ensaios, $\left.n^{\circ} 2\right)$

MAUÉS, Fernando. As ensinanças do livro do cavalgar. In: MONGELLI, Lênia Márcia (coord.). A literatura doutrinária na Corte de Avis. São Paulo: Martins Fontes, 2001. p. 201-242.

MEGIANI, Ana Paula Torres. O Rei ausente: festa e cultura política nas visitas dos Filipes a Portugal (1581 e 1619). São Paulo: Alameda, 2004.

MELO, Hildete Pereira de; MARQUES, Teresa Cristina de Novaes Marques. A partilha da riqueza na ordem patriarcal. Revista Econômica Contemporânea, Rio de Janeiro, v. 5, n. 2, p. 155-179, jul./dez. 2001.

MONGELLI, Lênia Márcia (coord.). A literatura doutrinária na Corte de Avis. São Paulo: Martins Fontes, 2001.

NASIO, Juan David. Lições sobre os 7 conceitos cruciais da psicanálise. Tradução de Vera Ribeiro. Rio de Janeiro: Jorge Zahar, 1989.

NOLASCO, Sócrates. De Tarzan a Homer Simpson: banalização e violência masculina em sociedades contemporâneas ocidentais. Rio de Janeiro: Rocco, 2001.

OLIVEIRA, Pedro Paulo. A construção social da masculinidade. Belo Horizonte; Rio de Janeiro: UFMG; IUPERJ, 2004.

PAIVA, José Pedro. As festas de corte em Portugal, no período Filipino (1580-1640). Revista de História da Sociedade e da Cultura, Coimbra, n. 2, p. 11-28, 2002.

PALMA-FERREIRA, João. Prefácio. In: VASCONCELOS, Jorge Ferreira de. Memorial das Proezas da Segunda Távola Redonda. Lisboa: Lello Editores, 1998 [1567]. p. VII-XVIII.

PEDRO, Joana Maria. Mulheres honestas e mulheres faladas: uma questão de classe. $2^{a}$ ed. Florianópolis: Ed. da UFSC, 1998.

PEDRO, Joana Maria. Traduzindo o debate: o uso da categoria gênero na pesquisa histórica. História, São Paulo, v. 24, n.1, p. 77-98, 2005. 
PERROT, Michelle. Mulheres públicas. São Paulo: Unesp, 1998.

RAMÍREZ, Maria Isabel Montoya. Introdução. In: ALFONSO XI. Libro de la montería. Est. y ed. crítica por Maria Isabel Montoya Ramírez. Granada: Universidad de Granada, 1992. p. 8-25.

SAMARA, Eni de Mesquita. Família, mulheres e povoamento: SP, século XVIII. Bauru: EDUSC, 2003.

SCOTT, Joan W. Gênero: uma categoria útil de análise histórica. Educação \& Realidade, Porto Alegre, v. 20, n. 2, p. 71-99, jul./dez. 1995.

SCOTT, Joan W. Experiência. In: SILVA, Alcione Leite da; SOUZA LAGO, Mara Coelho de; RAMOS, Tânia Regina Oliveira (org.). Falas de gênero: teorias, análises, leituras. Florianópolis: Mulheres, 1999. p. 21-55.

SCOTT, Joan W. O enigma da igualdade. Revista de Estudos Feministas, Florianópolis, v 13, n. 1, p. 11-30, jan./abr. 2005

SOUZA, Risonete Batista de. Montaria: a saborosa arte de formar o cavaleiro. In: MONGELLI, Lênia Márcia (coord.). A literatura doutrinária na Corte de Avis. São Paulo: Martins Fontes, 2001a. p. 155-200.

SOUZA, Risonete Batista de. O nobre jogo de andar ao monte e a ensinança das virtudes cavaleirescas. In: IV Encontro Internacional de Estudos Medievais, 2003, Belo Horizonte. IV Encontro Internacional de Estudos Medievais. Belo Horizonte: PUC Minas, 2001b. p. 706-714.

SCHPUN, Mônica Raisa (org.). Masculinidades. São Paulo: Boitempo, 2004.

SOIHET, Rachel; PEDRO, Joana Maria. A emergência da pesquisa da história das mulheres e das relações de gênero. Revista Brasileira de História, São Paulo, v. 27, n. 54, p. 281-300, 2007.

VASCONCELOS, Jorge Ferreira de. Memorial das Proezas da Segunda Távola Redonda. Lisboa: Lello Editores, 1998 [1567].

VIANA JÚNIOR, Mário Martins. Masculinidades: ampliando o debate. Revista Fórum identidades, Itabaiana, v. 23, p. 87-108, jan./abr. 2017.

WILSHIRE, Donna. Os usos do mito, da imagem e do corpo da mulher na reimaginação do conhecimento. In: JAGGAR, Alison; BORDO, Susan (org.). Gênero/ corpo/ conhecimento. Rio de Janeiro: Rosa dos Tempos, 1997. p. 101-125.

WITTIG, Monique. La pensée straight. Paris: Editions Amsterdam, 2007. 
WOLFF, Cristina Scheibe; PEDRO, Joana Maria; VEIGA, Ana Maria da (org.). Resistências, Gênero e Feminismos contra as Ditaduras no Cone Sul. Volume 1. Florianópolis: Mulheres, 2011.

\section{NOTAS}

\section{AUTORIA}

Mário Martins Viana Júnior: Doutor. Professor adjunto, Universidade Federal do Ceará, Centro de Humanidades, Departamento de História, Fortaleza, CE, Brasil.

Patrícia Rosalba Salvador Moura Costa: Doutora. Professora adjunta, Universidade Federal do Sergipe, Programa de Pós-Graduação em Antropologia, Núcleo de Educação em Ciências Agrárias e da Terra, São Cristóvão, SE, Brasil.

\section{ENDEREÇO PARA CORRESPONDÊNCIA}

Mário Martins Viana Júnior: Rua João Carvalho, 27, apto 1102, 60140-140, Fortaleza, CE, Brasil.

\section{ORIGEM DO ARTIGO}

Parte do artigo foi extraído da tese "Masculinidades compósitas nas capitanias do Norte da América portuguesa (séculos XVI e XVII)", apresentada ao Programa de Pós-Graduação em História da Universidade Federal de Santa Catarina, em 2013.

\section{AGRADECIMENTOS}

Agradecemos às professoras Joana Maria Pedro e Roselane Neckel.

\section{CONTRIBUIÇÃO DE AUTORIA}

Concepção e elaboração do manuscrito: M. M. Viana Júnior

Coleta de dados: M. M. Viana Júnior

Análise de dados: M. M. Viana Júnior; P. R. S. M. Costa

Discussão dos resultados: M. M. Viana Júnior; P. R. S. M. Costa

Revisão e aprovação: M. M. Viana Júnior; P. R. S. M. Costa

\section{FINANCIAMENTO}

Este artigo contou com financiamento da Coordenação de Aperfeiçoamento de Pessoal de Nível Superior (CAPES).

\section{APROVAÇÃO DE COMITÊ DE ÉTICA EM PESQUISA}

Não se aplica.

\section{CONFLITO DE INTERESSES}

Não houve conflito de interesses.

\section{LICENÇA DE USO}

Este artigo está licenciado sob a Licença Creative Commons CC-BY. Com essa licença você pode compartilhar, adaptar e criar para qualquer fim, desde que atribua a autoria da obra.

\section{PUBLISHER}

Universidade Federal de Santa Catarina. Programa de Pós-Graduação em História. Portal de Periódicos UFSC. As ideias expressadas neste artigo são de responsabilidade de seus autores, não representando, necessariamente, a opinião dos editores ou da universidade.

\section{EDITORES}

Flávia Florentino Varella (Editora-chefe)

Tiago Kramer de Oliveira

Waldomiro Lourenço da Silva Júnior 


\section{HISTÓRICO}

Recebido em: 16 de dezembro de 2019

Aprovado em: 25 de maio de 2020

Como citar: VIANA JÚNIOR, Mário Martins; COSTA, Patrícia Rosalba Salvador Moura. Representação régia: uma questão de gênero (séculos XV-XVII). Esboços, Florianópolis, v. 27, n. 46, p. 472-493, set./dez. 2020. 